\title{
PRESERVAÇÃO DA INFORMAÇÃO: GERENCIAR PARA POSSIBILITAR O ACESSO
}

\author{
PRESERVACIÓN DE LA INFORMACIÓN: ADMINISTRAR \\ PARA HABILITAR EL ACCESO
}

\section{Luana de Almeida Nascimento*}

\begin{abstract}
RESUMO
Introdução: Apresenta as reflexões acerca da preservação da informação sob a ótica dos autores da Arquivologia e da Ciência da Informação.

Objetivo: Apresenta uma revisão teórico-conceitual da preservação da informação com base nos teóricos da "Preservation of Information Specialization" da Universidade de Michigan apontados por Silva (2008).

Metodologia: Revisão teórico-conceitual de literatura referente à temática de preservação da informação.

Resultados: Apresenta a atual tendência mundial que vem reconhecendo a preservação como uma noção ampla, muito além do tratamento dos suportes documentais.

Conclusões: Com base nos estudos realizados conclui-se que, em tal abordagem, a preservação é compreendida como uma função arquivística dentro do escopo da gestão de documentos, condição necessária frente à impossibilidade de se gerenciar e preservar tudo que é produzido aliado à necessidade das atuais e futuras gerações de acesso à informação.
\end{abstract}

Palavras-chave: Preservação da informação. Acesso à informação. Arquivologia.

1 Mais informações sobre o programa disponíveis em: <http://www.si.umich.edu/msi/pi.htm>. Acesso em: 27. jan. 2016.

* Mestra em Ciência da Informação pela Universidade Federal Fluminense (UFF). Militar arquivista chefe da Seção de Arquivo Geral do Departamento de Controle do Espaço Aéreo (DECEA). Comando da Aeronáutica. E-mail: luana.arquivunesp@gmail.com. 


\section{INTRODUÇÃO}

Este artigo busca a revisão conceitual da noção de preservação da informação, com base nas leituras e discussões realizadas na disciplina "Preservação da Informação" do Programa de Pós-graduação em Ciência da Informação da Universidade Federal Fluminense, e pontuar algumas reflexões e hipóteses resultantes de tal processo. Optou-se por tratar o tema com base na concepção teórica preconizada pelos teóricos da "Preservation of Information Specialization" da Universidade de Michigan, abordados pelo Dro Sérgio Conde de Albite Silva em suas diversas publicações e que abarcam a definição e aplicação da preservação que julgamos coerente à necessidade do campo informacional.

Entende-se, desta maneira, a preservação da informação como função estratégica integrada aos procedimentos realizados no conjunto de ações da gestão documental no interior dos arquivos, ação esta sob responsabilidade do arquivista e que forneceria possibilidades de acesso futuro à informação arquivística².

O termo 'possibilidade' em detrimento à 'garantia', recorrente na literatura foi escolhido já que representa importante aspecto para a compreensão da preservação da informação de acordo com tal abordagem. Nesse caso, os procedimentos executados assim como as demais ações previstas nos procedimentos de gerenciamento da informação são indicativos da possibilidade de posterior acesso à informação que é hoje gerenciada. Desta forma, busca-se desconstruir a idéia de que ações isoladas e restritas de preservação são eficientes para possibilitar o acesso à informação.

Assim, o pressuposto norteador deste artigo é o entendimento que a base para 0 gerenciamento da informação arquivística (considerando que a preservação permeia todo processo de gestão) são

\footnotetext{
2 A noção de informação arquivística pode ser entendida como "[...] aquela produzida, recebida e acumulada por um organismo em razão das competências e atividades necessárias para a realização de seus objetivos." (SILVA, 2008, p. 45)
} 
as escolhas (uma vez que é impossível gerenciar - e preservar - a totalidade do que é produzido pela humanidade). Para tanto, faz-se necessário uma revisão do quadro teórico-conceitual da preservação da informação e dos temas concernentes à gestão informacional.

\section{PRESERVAÇÃO DA INFORMAÇÃO: REVISÃO TEÓRICO- CONCEITUAL}

A preservação, historicamente, foi vinculada diretamente aos procedimentos de tratamento tanto em conjuntos documentais quanto nos arquitetônicos com a finalidade de recuperar danos físicos dos suportes. Já no âmbito dos arquivos, o Dicionário Brasileiro de Terminologia Arquivística define preservação como a "Prevenção da deterioração e danos em documentos, por meio de adequado controle ambiental e/ou tratamento físico ou químico." (ARQUIVO NACIONAL, 2005, p. 135).

Pode-se observar que a ideia do significado da preservação apresenta-se como um procedimento estritamente ligado ao controle ambiental e tratamento físico/químico, dando margem para uma confusão bastante comum entre os significados dos termos "preservação", "conservação" e "restauração".

Silva (2008, p. 74) salienta que poucas são as abordagens teóricas acerca da preservação e que estas, em sua grande maioria, versam sobre a proteção do dito patrimônio artístico, monumentos arquitetônicos dentre outros. Nesse sentido, são raros os autores que abarcam a questão da preservação da informação e que "O reflexo mais evidente disso é que a terminologia da área se mantém com um considerável grau de nebulosidade."

Silva (2008, p. 75), ainda acrescenta que:

O quadro conceitual que envolve procedimentos do que se convencionou chamar de preservação só recentemente começa a se delinear de forma mais clara, com a adesão de alguns países europeus, como a França e a Inglaterra, aos métodos e técnicas preconizados pela chamada conservação preventiva. 
Aos poucos, seguindo linha de trabalho desenvolvida a partir dos Estados Unidos, em oposição à nossa matriz cultural européia, vão se firmando os conceitos referentes à preservação, conservação e restauração de bens culturais móveis, bem como o da conservação preventiva, o mais recente de todos.

Silva (2008, p. 74) versa sobre o significado entre os termos 'preservação, conservação e restauração'. Conservación corresponde ao conservation/preservation (no Inglês) e a conservation (em Francês). Já o especialista em conservación tem como correspondente o conservator/conservation scientist (Inglês) ou o professionnel de la conservation (Francês). O conservator atua tanto na conservação quanto na preservação, e o restorer, apenas na restauração.

Durante aula expositiva, Silva (2010, slide 1, grifo nosso) definiu conservação como "Conjunto de procedimentos que tem por objetivo melhorar o estado físico do suporte dos documentos, possibilitando o acesso à informação pelas futuras gerações" e restauração como "Conjunto de procedimentos que visa recuperar o estado original do suporte do documento, mantendo sua unidade informacional." Froner e Rosado comentam ainda que:

De fato, o conceito não é totalmente novo. Estava no ar há muito tempo, tempo demais. Já no século XIX Adolphe Napoleón Didron escreveu: conservar o máximo possível, reparar o menos possível e não restaurar por preço nenhum, deixando entender que seria preciso intervir o menos possível sobre o objeto para assegurar a autenticidade de sua mensagem. (FRONER; ROSADO, 2008, p. 13).

Considerando que a restauração, ou seja, as intervenções físico/químicas nos documentos, não correspondem a uma tarefa arquivística uma vez que o arquivista não é instruído em sua formação para tal, em detrimento da conservação preventiva, tarefa típica da gestão de arquivos, nota-se que a preservação é bem mais abrangente, isto é: "[...] conjunto de decisões estratégicas, que envolve opções políticas e tecnológicas, como, por exemplo, a reformatação de suporte por meio da microfilmagem e da digitalização." (SILVA, 2008, p. 75). 
Nossa proposta, assim como a dos autores aqui referenciados, é a de reforçar a perspectiva de uma preservação abrangente que contemple além do suporte o conteúdo informacional. Em tal abordagem, Wilson e Soy (2000) consideram que "[...] preservação é um estado mental, muito além da seleção de itens individuais para salvaguarda." (WILSON; SOY, 2000, p. 1, tradução nossa). Destaca-se a expressão "estado mental" por considerar que a preservação deve ser um desejo consciente (mental) e dotado de intencionalidade, uma vez que demanda planejamento, custos, aparato tecnológico, recursos humanos dentre tantas outras características a serem abordadas.

Helen Forde também comenta algumas das características da preservação:

A totalidade dos processos e operações envolvidas na estabilização e proteção dos documentos contra danos ou deterioração e no tratamento de danos ou documentos deteriorados. Preservação também pode incluir a transferência de informação para outro suporte, como o microfilme. (FORDE, 1999, p. 21, tradução nossa).

Conway (1990, p. 206, tradução nossa), por sua vez, acrescenta a distribuição de recursos "[...] humanos, físicos e monetários" como importantes aspectos da preservação tendo em vista que:

A essência do gerenciamento de preservação está na alocação de recursos. Pessoas, fundos e materiais devem ser requeridos, organizados e postos em operação para assegurar que será dada proteção adequada às fontes de informação. A preservação preocupa-se com os objetos propriamente ditos e com a evidência - que Michael Buckland (1991) chama de 'informação enquanto coisa' - embutida no conteúdo intelectual dos objetos. Investimentos eficazes em processos de preservação não podem ser adotados sem um compromisso com a obtenção de resultados reais. (CONWAY, 2001, p. 14).

Nota-se, portanto, que a abordagem da preservação apresentada busca muito mais do que a estabilidade dos suportes documentais. Mostra-se como uma noção ampla que requer administração para ter 
condições de ser uma ação contínua. Nesse sentido, Paul Conway acrescenta que a preservação prevê gerenciamento dos custos envolvidos nas ações preservacionistas com vistas à "[...] proteção adequada à informação histórica de valor duradouro para acesso pelas gerações atuais e futuras." (CONWAY, 2001, p. 49, tradução nossa).

A idéia de valor duradouro permeia toda a investigação acerca da preservação. Conforme citado anteriormente, as decisões relacionadas à preservação que hoje são tomadas objetivam possibilitar o acesso presente e futuro dos conjuntos documentais e de seu conteúdo informacional. Ao abordar sobre a idéia de permanência, recorrente no pensamento arquivístico e também na questão da preservação, O’Tolle (1989) critica a falta de reflexão por parte dos arquivistas em compreender, definir e controlar o uso de termos como "definitivo" e "permanente" dentre tantos outros de uso recorrente no campo arquivístico.

A falsa impressão de que a preservação garante o acesso e mantêm os acervos 'definitivamente preservados' são muito comuns. O'Tolle questiona que:

Mas o que os arquivistas realmente querem dizer quando falam sobre suas participações com os registros permanentes? Como observou Leonard Raport permanente é 'um termo conveniente para que nenhum substituto venha à mente'. A intemporalidade de um termo é difícil de entender, mas, a idéia de permanência, no entanto, oferece todos os confortos de qualquer absoluto. O significado de uma palavra é tão evidente, por que deveria nos preocupar? Dizer que os registros de arquivo são permanentes parece fixar o seu caráter de independência e de estabelecer, além do desafio, toda a extensão da responsabilidade do arquivista para eles. (O'TOLLE, 1989, p. 477, tradução nossa).

Desta forma, entende-se que se preserva hoje para um possível acesso no futuro. Que a preservação é uma ação contínua e, para tanto, requer planejamento e custos para dar conta do caráter contínuo e, além disso, deve estar integrada aos demais fazeres arquivísticos sendo considerado desde a produção até a destinação final dos documentos. 
O'Tolle acrescenta ainda que "Preservar documentos foi certamente útil, mas não acabou tão importante quanto preservar informações." (O'TOLLE, 1989, p. 482, tradução nossa).

Rousseau e Couture (1998) explicam que a trajetória dos arquivos está diretamente ligada à história dos suportes informacionais administrativos. Pontuam ainda que os "[...] novos suportes electrónicos de que o século $X X$ se dotou apresentam, [...], características revolucionárias para a informação."

Neste caso, os novos suportes informacionais fomentariam discussões dando margem às novas abordagens no campo arquivístico no que tange a questão da produção, organização dentre tantos outros aspectos,

Sabe-se já que tem a vantagem de permitir um maior armazenamento e de facilitar a difusão [da informação]. Tecnicamente frágeis, levantam novos problemas relativos à organização da informação, bem como sua conservação. Eles exigem uma nova especialização por parte dos gestores da informação. (ROUSSEAU; COUTURE, 1998, p. 40).

Observa-se que, de acordo com a afirmação de Rousseau e Couture (1998), o cenário arquivístico atual implica um reconhecimento (ou o que os autores entendem por especialização) do real campo de atuação do arquivista para atender as demandas da sociedade contemporânea na qual a inserção das tecnologias de informação e comunicação (TIC's) juntamente com a diversidade dos suportes informacionais trazem à tona a necessidade de ampliação dos preceitos arquivísticos e de uma real postura de gestor por parte do arquivista.

Portanto, com base em tais definições e hipóteses apresentadas, busca-se compreender alguns aspectos de como a questão da informação vem se tornando central nos arquivos e em que medida a preservação é inserida em tal contexto, como esta ocupa espaço central quando se objetiva o acesso à informação e de que modo é caracterizada enquanto função arquivística integrada à gestão nos arquivos. 


\section{PRESERVAÇÃO E GESTÃO DE DOCUMENTOS: AÇÕES ESTRATÉGICAS PARA POSSIBILITAR O ACESSO À INFORMAÇÃO}

Considerando que o acesso à informação é um dos aspectos norteadores de todo pensar e fazer arquivístico e que a preservação é uma questão central para possibilitar o sucesso de tal meta, faz-se necessário observar como a literatura da área aborda a questão da preservação inserida no contexto de ações estratégicas que compõem o corpus da gestão. Silva (2008) lembra que só atualmente começam a ser produzidos estudos que associam a preservação à gestão de documentos.

A prática de organização de arquivos ocorre desde os tempos mais remotos, entretanto, o patamar disciplinar tem como uma das marcas iniciais a publicação do que ficou conhecido como Manual dos arquivistas holandeses ${ }^{3}$, publicação que privilegiou a normalização das práticas arquivísticas realizadas dentro de uma estrutura institucional.

O modelo de instituição arquivística característico dos primeiros movimentos do campo arquivística já com status disciplinar era essencialmente voltado para a custódia de documentos produzidos pelo Estado. Silva (2009, p. 20) explica que:

Contudo, a partir do século XIX, a visão histórica dos arquivos relaciona-se com a invenção das tradições nacionais, como via explicativa para a constituição de um modelo de instituição arquivística para custódia de acervos culturalmente importantes de um país - um movimento significativamente reproduzido durante 0 século XIX no Ocidente.

O autor comenta ainda que as instituições arquivísticas inseridas no contexto do século XIX priorizavam a preservação e o acesso aos documentos, em sua maioria de origem pública, sob sua

${ }^{3}$ ASSOCIAÇÃO DOS ARQUIVISTAS HOLANDESES. Manual de arranjo e descrição de arquivos. Rio de Janeiro: Arquivo Nacional, 1993. (Série Publicações Técnicas, 47). 
responsabilidade. É predominante a preocupação com o arquivo enquanto local de custódia e centralização do dito 'patrimônio documental' da nação, conforme pode ser observado no caso francês de criação de um arquivo de abrangência nacional (SILVA, 2009). Armando Malheiro (2010) denomina essa primeira fase do campo arquivístico como 'Fase Sincrética ${ }^{4}$ e Custodial'.

Nesse sentido, salientamos como principais características deste primeiro enfoque da Arquivística enquanto disciplina e sob a perspectiva apresentada por Silva (2009) o caráter custodiador dos arquivos públicos, o aspecto centralizador (bem como estratégico) dos Arquivos Nacionais, as práticas arquivísticas como ferramentas de tratamento das fontes primárias e o forte viés auxiliar para a História dentre outras características. Sobre o tema, Armando Malheiro ainda acrescenta que:

Foi acolhida no seio da História, chegando a receber o epíteto de 'ciência auxiliar', mas, em rigor e durante o século XIX, coube, junto com a paleografia, a diplomática e a codicologia, a numismática, a arqueologia, a epigrafia, a sigilografia, a cronologia, a bibliologia etc, dentro do leque amplo de ingredientes heurísticos e críticos do método da ciência histórica. (SILVA, 2010, slide 20).

Entretanto, na primeira metade do século XX ocorre um crescimento exponencial da massa documental produzida não só pelo Estado, mas, principalmente, pelas agências ligadas direta e indiretamente aos setores de ciência e tecnologia, fatores que impulsionaram o deslocamento do enfoque histórico dos arquivos para uma visão voltada ao gerenciamento de acervos.

No período localizado na primeira metade do século XX deparase com um cenário no qual o aumento do conjunto documental produzido, considerando a complexificação dos processos de trabalho e do forte crescimento dos setores científicos e tecnológicos da época,

\footnotetext{
4 "Sincrético: 1. Relativo ao, ou em que há sincretismo [...]. Sincretismo: 1. Reunião artificial de ideias ou de teses de origens disparatas [...]." (FERREIRA, 1986. p. 1589).
} 
bem como a necessidade de mecanismos de racionalização de todos os processos, demanda de eficiência e eficácia administrativas e transparência das ações do Estado. Nota-se a mudança da abordagem histórica para um enfoque gerencial nos arquivos. De acordo com Eliezer Silva:

A visão gerencial estabeleceria uma ampliação das funções arquivísticas. A demanda de eficiência estatal, frente aos problemas de 'explosão documental' por parte dos países desenvolvidos no período chamado entre Guerras e o ambiente de difusão das idéias de administração científica delineariam o surgimento do conceito e das práticas de gestão de documentos ${ }^{5}$. (SILVA, 2009, p. 19).

Considerando tal contexto, Fonseca (2005, p. 43-44) destaca algumas características da Arquivologia em tal período enquanto "[...] disciplina inserida nos princípios de racionalidade administrativa e, portanto, associada aos princípios de eficácia da modernidade política é a ruptura que se estabelece ao se inaugurarem as práticas denominadas records management ou gestão de documentos."

Maria Odila Fonseca (2005, p. 46) ressalta, considerando os contextos da arquivística norte-americana em contraponto com a tradição de alguns países anglo-saxônicos que, considerando o campo de atuação dos arquivos dito permanentes e o da gestão de documentos havia a seguinte distinção "[...] arquivistas, profissionais encarregados dos arquivos permanentes, e records managers, profissionais encarregados da gestão de documentos [...]". A autora cita ainda que a definição de gestão de documento de acordo com a legislação norteamericana é:

5 De acordo com o Art. 3ํ da Lei 8.159 de 1991 que dispõe sobre a política nacional de arquivos afirma que "Considera-se gestão de documentos o conjunto de procedimentos e operações técnicas à sua produção, tramitação, uso, avaliação e arquivamento em fase corrente e intermediária, visando a sua eliminação ou recolhimento para guarda permanente." (BRASIL, 1991). 
[...] o planejamento, o controle, a direção, a organização, o treinamento, a promoção e outras atividades gerenciais ligadas à criação, manutenção ${ }^{6}$, uso e eliminação de documentos, com a finalidade de obter registro adequado e apropriado das ações e transações do governo federal efetiva e econômica gestão das operações das agências. (FONSECA, 2005, p. 44).

Por outro lado, cabe ressaltar a contribuição de Theodore Roosevelt Schellemberg ${ }^{7}$ através da perspectiva do ciclo de vida dos documentos no qual o autor apresenta sua constatação a respeito do valor primário dos arquivos ativos e semi-ativos (de uso corrente e intermediário) e da necessidade de classificá-los e avaliá-los junto à sua origem, o que proporcionaria uma redução na quantidade de documentos a serem mantidos por um período duradouro.

A questão do ciclo de vida dos documentos mostra-se como central no bojo da gestão de documentos conforme Rondinelli (2005, p. 41) cita:

[...] os documentos são primeiramente organizados, mantidos e usados ativamente por seus criadores, depois são armazenados por um período adicional de uso não freqüente $\mathrm{e}$, finalmente, quando seu uso operacional termina completamente, são selecionados como valor arquivístico e transferidos para um arquivo ou declarados sem valor e destruídos.

Conforme pode ser observado nas definições de 'gestão de documentos' apresentada por Fonseca (2005) e Rondinelli (2005) os termos 'manutenção' e 'mantidos' estão em destaque. A partir do significado do termo Manutenção: "1. Ato ou efeito de manter-se; 2. As medidas necessárias para a conservação ou permanência de alguma coisa ou de alguma situação [...]" pode-se inferir que, indiretamente, quando as autoras citam a manutenção como uma das funções

6 "Manutenção: 1. Ato ou efeito de manter-se; 2. As medidas necessárias para a conservação ou a permanência de alguma coisa [...]." (FERREIRA, 1986, p. 1084)

7 SCHELLEMBERG, Theodore Roosevelt. Arquivos modernos: teoria e prática. 6 . ed. Rio de Janeiro: FGV, 2006. 
arquivísticas ligadas à gestão de documentos elas falam da preservação de acordo com as definições apresentadas no item 2 deste trabalho.

Silva (2008, p. 99), considerando a preservação como função arquivística, cita os trabalhos de Terry Cook que relacionam a pósmodernidade e a Arquivística e explica que "[...] Cook (2000, p. 12) identifica um rompimento paradigmático e a necessidade de novas abordagens na área, de tal forma que a Arquivística dê conta da análise das propriedades e características dos documentos, de suas funções, processos e transações no século XXI."

Considerando que os métodos tradicionais $\mathrm{e}$ isolados de preservação já não são suficientes para a realidade arquivística, Terry Cook enfatiza que:

Os métodos tradicionais de preservação de documentos de arquivo eram baseados em padrões apropriados de reparo, restauração e uso dos suportes físicos. Com os documentos eletrônicos, os suportes físicos tornam-se quase que totalmente irrelevantes, na medida em que os documentos terão seus conteúdos migrados muito antes da deterioração física de seus suportes. O que passa a ser importante é a reconfiguração do documento original em relação à sua funcionalidade, proveniência e originalidade, e é sobre estes problemas que os arquivistas terão que focar a sua atenção. (COOK, 1997 apud SILVA, 2008, p. 100, tradução do autor).

Considerar a preservação uma das funções arquivísticas implica considerá-la no mesmo patamar de tarefas já consagradas pelos teóricos da área (como a classificação, avaliação, dentre outras). Silva (2008) lembra que, de acordo com tal perspectiva, a preservação que é ensinada nos cursos de Arquivologia deve voltar-se mais para o aspecto gerencial e do planejamento do que para intervenções físicas nos documentos.

Nessa mesma linha, Sherelyn Ogden (2001, p. 07) complementa que o planejamento de um programa de preservação não deve ser considerado enquanto algo complexo, que exija conhecimentos aprofundados por parte do arquivista sobre os componentes químicos dos materiais dentre demais conhecimentos técnicos. Muito pelo 
contrário, segundo o autor "[...] a tarefa assemelha-se muito a outros processos de decisão administrativa: trata-se da distribuição dos recursos disponíveis entre as atividades e funções mais importantes, de acordo com a ordem de prioridade na missão de uma instituição." Neste caso, a preservação deve ser pensada como uma das atividades recorrentes na gestão de documentos e integradas às demais atividades enquanto parte da administração de acervos.

Ingrid Beck (2006) ao tratar do tema do ensino da preservação documental nos cursos de Arquivologia e Biblioteconomia considera também a preservação sob uma perspectiva gerencial e integrada com as demais atividades realizadas. A autora afirma que "A preservação requer administração, e não restauração [...]" (ALBADA, 1987, apud BECK, 2006, p. 3) e que, sob o aspecto administrativo da preservação, convêm estabelecer planejamento e prioridades sobre os recursos envolvidos em tal atividade.

Mais do que uma atividade de forte cunho gerencial, a preservação é orientada também pelo planejamento e decisões de forte aspecto político. Nesse sentido, Silva (2008) explica que:

A preservação por ser necessariamente contínua, vincula-se hoje muito mais ao planejamento e às decisões e escolhas políticas do que as intervenções pontuais para a recuperação de danos de acervos. A compreensão disso faz toda a diferença naquilo que se entende e se pretende como preservação. A preservação está muito mais próxima dos que tomam as decisões, promovem as políticas e disputam os orçamentos do que daqueles que intervêm nos acervos. (SILVA, 2008, p. 243).

Para Paul Conway a preservação, hoje, é uma noção que abarca inúmeras políticas e opções de ação, incluem os tratamentos de conservação, a aquisição, a organização, a distribuição e a operacionalização de recursos humanos, financeiros e o início da deterioração e de renovar a possibilidade de utilização dos acervos dentro do que chama gerenciamento de preservação. A preservação se 
preocupa com os suportes, mas em função do seu uso e conteúdo informacional. (SILVA, 2008, p. 75).

Conforme já citado anteriormente, a preservação de acordo com a perspectiva apresentada prevê administração de recursos humanos, financeiros e materiais tendo em vista a necessidade de preservação contínua e a longo prazo e a questão do acesso à informação. Nesse sentido, a administração dos custos envolvidos em tal processo é incontornável.

Helen Forde (1999) observa que manter a informação acessível, não só no aspecto do acesso físico e sim do conteúdo informacional dos documentos, envolve inúmeros custos. Ressalta também que tradicionalmente a preservação encontra-se desagregada aos demais fazeres arquivísticos comprometendo, por tanto, aspectos caros à preservação como a questão da continuidade. A autora argumenta ainda que "Sem as estratégias de preservação, o acesso aos documentos não será possível e estes, ao deixarem de existir, direitos humanos básicos seriam negados. Quando os profissionais, do primeiro ao último escalão, entenderem isso, as medidas de preservação serão muito mais eficazes." (FORDE, 1999, p. 21-29, tradução nossa)

Os aspectos ligados à questão da continuidade da preservação estão diretamente ligados à propagação das tecnologias disponíveis de informação e comunicação. Silva (2008) explica ainda que tais mudanças impulsionaram tal aproximação, fato que resultou na idéia da preservação contínua e a longo prazo. O autor afirma que:

Por preservação contínua e a longo prazo entende-se o conjunto de ações implementadas para garantir durabilidade e permanência aos suportes que contêm informação. Tais ações constituem um amplo espectro de atividades, estratégias e decisões que reúnem desde as possibilidades oferecidas pela plataforma tecnológica disponível (intervenções de conservação física, microfilmagem, digitalização, reformatação e reprodução etc.) até planejamentos, programas e projetos que envolvem responsabilidades técnicas, administrativas, recursos financeiros e humanos. A preservação é caracterizada por ser uma intervenção abrangente e que requer continuidade no tempo. Isso se torna premente com as novas tecnologias de 
informação e comunicação, por que a recuperação da informação registrada nesses novos suportes exige que, além da preservação desses novos materiais, sejam preservados também os respectivos elementos lógicos (software, aplicativos, sistemas operacionais, redes etc.). Para isso, a preservação não pode ser mais realizada de forma intermitente e inconstante. (SILVA, 2008, p. 85).

Com base na revisão teórico-conceitual acerca da preservação e de sua compreensão enquanto tarefa da gestão de documentos com vistas ao acesso à informação, algumas reflexões e hipóteses surgiram no decorrer do processo. O tema da preservação da informação ainda requer aprofundamento teórico em vários aspectos, muitas lacunas ainda estão em aberto. Mais do que buscar soluções e certezas, o trabalho realizado visa uma compreensão geral do tema e abrir novos campos de discussão.

\section{CONSIDERAÇÕES FINAIS}

A preservação da informação, principalmente quando consideradas as características da informação de natureza arquivística, encontra vasto campo de investigação prática e teórica tendo em vista, ainda que empiricamente, que a possibilidade de acesso aos documentos não corresponde ao acesso à informação contida nos mesmos. Ingrid Beck reforça tal afirmação ao citar que "O objetivo é mais do que a acessibilidade, é também a qualidade arquivística, que se relaciona à transparência e à permanência da informação." (THOMASSEN, 1999 apud BECK, 2006, p. 19).

Justamente por privilegiar a possibilidade do acesso aos conteúdos informacionais (ligados à idéia de Beck sobre o que chamou de 'permanência da informação') é que encontramos espaço coerente de discussão nos estudos realizados pelo Dr. Sérgio Conde de Albite Silva e os pesquisadores da Universidade de Michigan assim como os demais autores destacados neste trabalho.

O enfoque informacional nos arquivos é bastante recente. Alguns anteriormente citados já abarcam a idéia de preservação mais ampla, 
interligada às demais tarefas arquivísticas e de caráter contínuo. Um dos exemplos é Helen Forde, que demonstra claramente a emergência da integração da preservação à gestão realizada nos arquivos. A autora comenta ainda que:

A preservação é uma atividade contínua para um arquivo e, a nível político e estratégico, elemento essencial na gestão de arquivos [...]. O mantra 'preservação dá suporte ao acesso' substitui conceitos menos usualmente amigáveis, mas ainda é insuficiente para reforçar a mensagem que sem preservação não pode haver acesso atual ou futuro para as informações. (FORDE, 1999, p. 1, tradução nossa).

Outra questão que nos chama atenção é a necessidade de considerar a permanência do conteúdo informacional nos documentos em suportes não-convencionais. $O$ caso do documento fotográfico ${ }^{8}$ merece atenção especial uma vez que, na maioria dos casos, este não é considerado documento arquivístico dotado de proveniência e organicidade em sua origem. Desta maneira, tais documentos são tratados como coleções reunidas artificialmente, perdendo-se, portanto, as características que os identificam enquanto arquivísticos.

Nesse sentido, nem as tarefas mais tradicionais da arquivística como a classificação, avaliação e descrição são realizadas conforme preconizado pelos teóricos da área. Conjuntos documentais inteiros são desmembrados de seus fundos sendo tratando enquanto peças únicas por conta muitas vezes da dificuldade, por parte do arquivista, em tratar das especificidades do suporte em detrimento da organicidade do conjunto.

Desta maneira, a abordagem apresentada acerca da preservação da informação mostra-se adequada quando tal situação é considerada. Isto ocorre porque de acordo com tal perspectiva a preocupação com o suporte, com a peça e com os tratamentos isolados é ínfima. Considera-

\footnotetext{
8 "Documento fotográfico: Fotografia em positivo ou negativo." (ARQUIVO NACIONAL,
} 2005, p. 68)

Inf. Prof., Londrina, v. 5, n. 1, p. 111 - 130, jan./jun. 2016

http:www.uel.br/revistas/infoprof/ 
se, portanto, a totalidade. Objetiva-se a permanência da informação e, tratando-se de um conjunto arquivístico, convém notar a permanência da organicidade do conjunto documental, independente do suporte.

A questão da preservação da organicidade é um aspecto incontornável à arquivística, mesmo que esta a tenha desconsiderado até pouco tempo. Cabe ressaltar também que esta desconsideração ocorre também por parte da ciência da informação que, por premissa, objetiva o acesso à informação. Neste sentido, Solange Zúñiga chama atenção para o seguinte aspecto:

Como seria possível imaginar o acesso e o uso da documentação/informação sem contar com as ações de preservação? É interessante notar esse 'repúdio', ou pelo menos esse 'alheamento' de um em relação ao outro, refletindo a ausência de menção à preservação na leitura dedicada à Ciência da Informação, sobretudo quando pensamos na documentação e na recuperação da informação como origens da Ciência da Informação. (ZÚÑIIGA, 2005, p. 23).

O acesso à informação, mais que um jargão, deve ser um norteador para as práticas arquivísticas, entretanto, vale lembrar também que mais importante do que possibilitar o acesso é dar acesso ao que Thomassen (1999 apud BECK, 2006) chama de 'qualidade arquivística'. O usuário deve ter condições de compreender o contexto no qual o conteúdo informacional está inserido, é isto que o torna arquivístico e o difere dos demais tipos de documentos.

Mais do que um simples custodiador de acervos, ou um 'reparador de papéis' é emergente que o arquivista reconheça o arquivo enquanto órgão central de um sistema de informações e de sua atuação profissional enquanto gestor, responsável pelo funcionamento de tal sistema. 


\section{REFERÊNCIAS}

ARQUIVO NACIONAL. (Brasil). Dicionário brasileiro de terminologia arquivística. Rio de Janeiro, 2005.

BECK, Ingrid. $O$ ensino da preservação documental nos cursos de arquivologia e biblioteconomia: perspectivas para formar um novo profissional. 2006. Dissertação (Mestrado em Ciência da Informação) Convênio Universidade Federal Fluminense com o Instituto Brasileiro de Informação em Ciência e Tecnologia, Instituto de Artes e Comunicação Social - UFF, Rio de Janeiro, 2006.

BRASIL. Lei no 8. 159, de 9 de janeiro de 1991. Dispõe sobre a política nacional de arquivos públicos e privados e dá outras providências.

Disponível em:

<http://www.conarq.arquivonacional.gov.br/cgi/cgilua.exe/sys/start.htm>. Acesso em: 12 nov. 2015.

CONWAY, Paul. Preservação no universo digital. 2. ed. Rio de Janeiro: Projeto Conservação Preventiva em Bibliotecas e Arquivos: Arquivo Nacional, 2001. (Conservação Preventiva em Bibliotecas e Arquivos, v. 52).

Archival preservation practice in a nationwide context. In:

American Archivist. N. 53 (Spring, 1990). p. 204-222.

FERREIRA, Aurélio B. de Hollanda. Novo dicionário da língua portuguesas. 2. Ed. Rio de Janeiro: Nova Fronteira, 1986.

FONSECA, Maria Odila Kahl. Arquivologia e ciência da informação. Rio de Janeiro: FGV, 2005.

FORDE, Helen. Preservation as a strategic function and an integrated component of archives management: or can we cope without it? In: INTERNATIONAL CONFERENCES OF THE ROUND TABLE ON ARCHIVES, 34., 1999, Budapest. Proceedings... Budapest: ICA, 1999, p. $21-29$

FRONER, Yacy-Ara Froner; ROSADO, Alessandra. Princípios históricos e filosóficos da conservação preventiva. Belo Horizonte: LACICOR - EBA - UFMG, 2008.

OGDEN, Sherelyn. Planejamento para preservação. 2. Ed. Rio de Janeiro: Projeto Conservação Preventiva em Bibliotecas e Arquivos: Arquivo Nacional, 2001. (Conservação Preventiva em Bibliotecas e Arquivos, v. 30).

O'TOLLE, James M. On the Idea of permanence. In: American archivist. n. 52 (Winter, 1989), p. 475-494. 
RONDINELLI, Rosely Curi. Gerenciamento arquivístico de documentos eletrônicos: uma abordagem teórica da disciplina arquivística contemporânea. 4. ed. Rio de Janeiro: FGV, 2005

ROUSSEAU, Jean-Yves; COUTURE, Carol. Os fundamentos da disciplina arquivística. Lisboa: Dom Quixote, 1998. 355p.

SCHELLENBERG, Theodore R. Arquivos modernos: princípios e técnicas. 6. ed. Rio de Janeiro: FGV, 2006. 388p.

SILVA, Armando Malheiro da. A Arquivologia pós-custodial e seu arcabouço teórico. Comunicação em formato .ppt apresentada no IV CNA, Vitória, 2010.

SILVA, Elizer Pires. A noção de informação arquivística na produção de conhecimento em Arquivologia no Brasil (1996 - 2006). 2009.

Dissertação (Mestrado em Ciência da Informação) - Convênio Universidade Federal Fluminense com o Instituto Brasileiro de Informação em Ciência e Tecnologia, Instituto de Artes e Comunicação Social - UFF, Rio de Janeiro, 2009.

SILVA, Sérgio Conde de Albite. A preservação da informação arquivística governamental nas políticas públicas do Brasil. Rio de Janeiro: AAB/FAPERJ, 2008.

WILSON, Paul; SOY, Susan K. Defining preservation: Introduction to preservation for libraries and archives. Fall, 2000.

ZÚÑIGA, Solange Sette Garcia de. Documentos como objeto de políticas públicas em preservação e acesso à informação: o caso das bibliotecas e arquivos. 2005. Tese (Doutorado em Ciência da Informação) - Convênio Universidade Federal Fluminense com o Instituto Brasileiro de Informação em Ciência e Tecnologia, Instituto de Artes e Comunicação Social - UFF, Rio de Janeiro, 2005.

Title

Preservation of information: manage to enable access

\section{Abstract}

Introduction: Presents the reflections on the preservation of information from the perspective of the authors of Archival and Information Science.

Objective: It presents a theoretical-conceptual review of preserving information based theorists of the "Preservation of Information Specialization" at the University of Michigan pointed out by Silva (2008).

Methodology: Theoretical and conceptual review of literature related to the theme of preservation of information.

Results: Displays the current global trend that has recognized the preservation as a broad concept, far beyond the treatment of documentary media. 
Conclusions: Based on studies it is concluded that, in such an approach, the preservation is understood as an archival function within the scope of document management, essential integration when it is noted that it is impossible to manage and preserve all that is produced ally the need for current and future generations of access to information.

Keywords: Preservation of information. Access to information. Archivology.

\section{Titulo}

Preservación de la información: administrar para habilitar el acceso

\section{Resumen}

Introducción: Presenta las reflexiones sobre la preservación de la información desde la perspectiva de los autores de Archivología y Documentación.

Objetivo: Se presenta una revisión teórica-conceptual de la preservación de los teóricos de la base de información de la "preservación de la información especialización" de la Universidad de Michigan señalada por Silva (2008).

Metodología: Revisión teórica y conceptual de la literatura relacionada con el tema de la conservación de la información.

Resultados: Muestra la actual tendencia mundial que ha reconocido la preservación como un concepto amplio, mucho más allá del tratamiento de los medios de comunicación documental.

Conclusiones: En base a los estudios, se concluye que, en este enfoque, la conservación se entiende como una función de archivo dentro del ámbito de la gestión de documentos, integración esencial cuando se observa que es imposible de gestionar y conservar todo lo que se produce aliado la necesidad de que las generaciones actuales y futuras de acceso a la información.

Palabras clave: Preservación de la información. El acceso a la información. Archivología.

Recebido em: 26.12.2015

Aceito em: 20.03.2016 